UCRL-ID-128420

\title{
EM Field and Instrumentation Diagnostics in Support of the LFT\&E HPM Methodology Testing
}

\author{
Scott D. Nelson
}

Robert A. Anderson

September 4, 1997

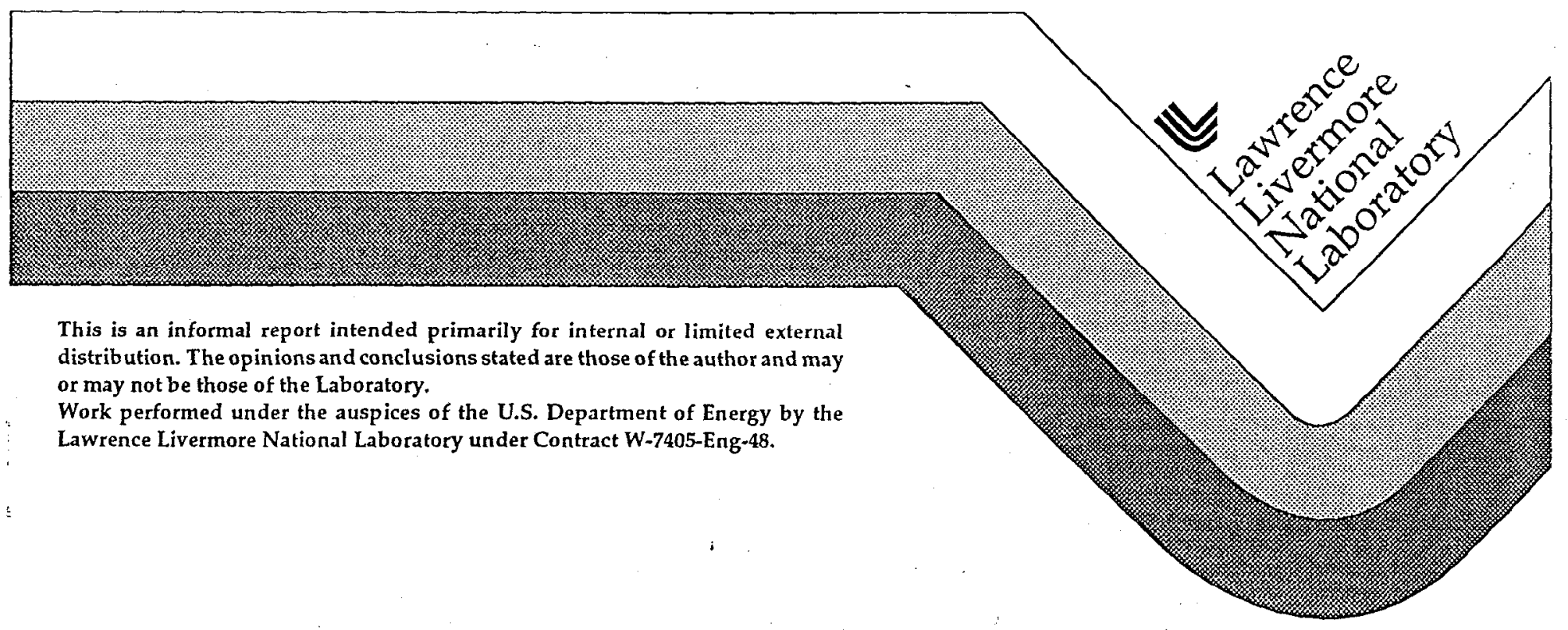




\section{DISCLAIMER}

This document was prepared as an account of work sponsored by an agency of the United States Government. Neither the United States Government nor the University of California nor any of their employees, makes any warranty, express or implied, or assumes any legal liability or responsibility for the accuracy, completeness, or usefulness of any information, apparatus, product, or process disclosed, or represents that its use would not infringe privately owned rights. Reference herein to any specific commercial product, process, or service by trade name, trademark, manufacturer, or otherwise, does not necessarily constitute or imply its endorsement, recommendation, or favoring by the United States Government or the University of California. The views and opinions of authors expressed herein do not necessarily state or reflect those of the United States Government or the University of California, and shall not be used for advertising or product endorsement purposes.

This report has been reproduced directly from the best available copy.

Available to DOE and DOE contractors from the Office of Scientific and Technical Information

P.O. Box 62, Oak Ridge, TN 37831

Prices available from (615) 576-8401, FTS 626-8401

Available to the public from the

National Technical Information Service

U.S. Department of Commerce

5285 Port Royal Rd.,

Springfield, VA 22161 


\title{
EM Field and Instrumentation Diagnostics in support of the LFT\&E HPM Methodology Testing
}

\author{
by \\ Scott D. Nelson and Robert A. Anderson \\ Lawrence Livermore National Laboratory
}

The Naval Air Warfare Center, China Lake, under the direction of the DoD LFT\&E Office performed a series of HPM tests for the purpose of exercising the HPM methodology for LFT\&E applications. An AH-1S Cobra helicopter was used as the canonical test bed. The Air Force Research Lab (formally Phillips Lab) provided the wide-band source and the Army Research Lab provided the narrow-band used in the tests. LLNL provided the EM diagnostics used at the site for both test series. Our mission was to measure the radiated field from the sources, measure the fields inside the helicopter and the coupling onto various signal lines inside the helicopter, and to monitor the various system signal levels for "bird health" purposes. These experiments were performed during June of 1997 and consisted of exposing the test bed to a series of narrow-band and wideband pulses from HPM sources.

This report covers the measured radiated fields, the fields inside the helicopter, and the coupled signal levels. The radiated fields were measured over a region which spans the physical body of the helicopter. The fields inside the helicopter and the coupled fields were measured using a series of probes inside the helicopter and connected to the outside measurement system using fiber-optic cables. The helicopter effects data are presented in the main China Lake report.

\section{INTRODUCTION}

This test was sponsored by the Live Fire Test and Evaluation (LFT\&E) Office which is part of the Office of Test and Evaluation (OT\&E) under the Office of the Secretary of Defense. The test consisted of an HPM test suite performed in FY97 at the China Lake Junction Ranch test facility. The test facility, Junction Ranch, NAWC, operated by the Radar Cross Section Outdoor Branch, Electronic Combat Range, at the Naval Air Warfare Center Weapons Division, China Lake, California, was selected as the location to conduct this test and China Lake served as the test director for these tests. The AH1S Cobra Helicopter was selected as the test object for these tests since it was available and was used in a similar capacity as part of the previous modeling validation expcriments performcd in FY96 at the same facility. The prime focus the HPM tests performed during FY97 was not to cause effects on the Cobra but the evaluate the test methodology used during the testing.

Two HPM sources (narrow-band and wide-band) were be used to illuminate the helicopter during which the fluence levels and effects were recorded. The plan involved the coordination of activities between NAWC, Lawrence Livermore National Lab- oratory (LLNL), the Air Force Research Lab (AFRL, formally Phillips Lab), and the Army Research Lab (ARL). NAWC was the prime for this testing, LLNL provided diagnostics and RF measurements, AFRL and ARL provided the sources.

The testing consisted of exposing the helicopter to energy from the pulser, measuring the transmitted waveforms, measuring the energy inside the helicopter, measuring the energy coupled to various signal lines inside the helicopter, and observing the effects on the helicopter. One objective of the test sequence that could not be accomplished (due to source and scheduling problems) was the monitoring of the analog waveforms on the various signal lines during exposure. These kinds of measurements would be part of a general LFT\&E measurement however since they provide the only mechanism for monitoring during an "upset" condition and provide the only indication of "bird health" for those instruments that do not have direct feedback to the crew. Other parts of the original test plan were greatly abbreviated due to scheduling as the testing procecded during the weeks. 


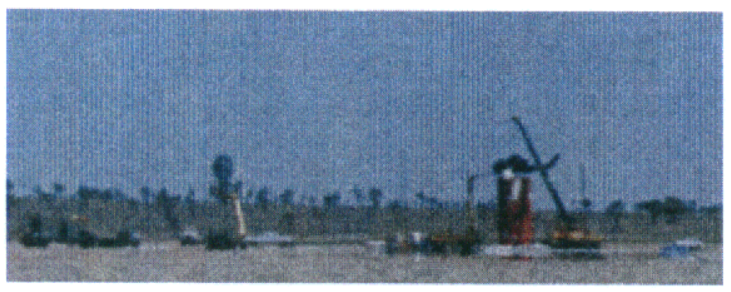

Figure 1. the test site during HPM testing

\section{BACKGROUND}

The test series had three principal motivations: (1) bring the instrumentation together needed for a LFT\&E facility, (2) perform a dry-run of the LFT\&E HPM methodology, and (3) evaluate the deficiencies in the testing process and take corrective action before a LFT\&E test on a real asset.

The purpose of LLNL's efforts was to set up and demonstrate the facility infrastructure needed for a LFT\&E HPM facility, monitor the RF fields during testing, and to characterize any affects observed. These may be summarized as a parallel to their ballistic counterparts:

1. characterize the size of the shotgun pellet and the spread of the burst

2. characterize the ballistic energy on-target

3. characterize the effects of the hole and damage

The prime difference between ballistic effects and HPM effects is that HPM effects come in two flavors: upset and damage. Damage, as it's name implies, is similar to the physical damage caused by a ballistic event -- specifically, components are damaged, burned-out, or shorted-out as a result of the energy deposited on them. Upset on the other hand is a transient phenomenon and an instrument may correct itself shortly after the RF exposure has ended. Since the goal of LFT\&E tests is to perform operational tests, then the test sequence should include methods for monitoring the mission critical systems during the testing. This difference is important because upset is usually much easier to cause than damage in electronic systems.

\section{APPROACH}

The experiments were conducted on an electrically complete and operational $\mathrm{AH}-1 \mathrm{~S}$ aircraft (except for the rotor blades and tail blades). The blades and tail blades were removed for operational safety reasons.

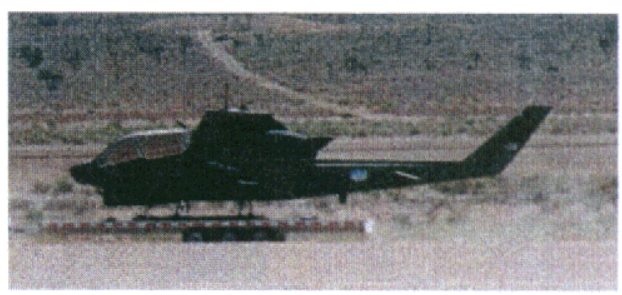

Figure 2. AH-1S \#139 with blades removed

One goal of the testing was to expose the helicopter to two polarizations (vertical and horizontal) using three illumination angles (from below, on-axis, and from above) but pulser issues and the tight schedule necessitated only a subset of this. In the wide-band case this was vertical polarization and on-axis illumination. For the narrow-band pulser, both vertical and horizontal polarizations were used with on-axis illumination.

The LLNL instrumentation outside of the helicopter measured the field levels during the pulsing. Additionally, a scan was taken across the body of the helicopter to sample the energy distribution and determine the coverage from the HPM pulser insitu. The probes inside the helicopter monitored the energy inside the helicopter and the energy coupled to some of the signal lines inside the helicopter. As was mentioned previously, the signal levels of the equipment were not monitored due to problems. In general, this kind of data is very valuable for determining effects.

To summarize, the LLNL test sequence for the facilities measurement consisted of:

1. test object is activated

2. HPM source is activated

3. energy is transmitted

4. RF energy is picked up by the LLNL master trigger and starts it's journey towards the LLNL diagnostic system. It must arrive 100 ns ahead of the actual RF signals to be measured

5. RF waveform is recorded on LLNL external probes and starts it journey towards the LLNL diagnostic system

6. RF energy arrives at the test object

7. some energy couples into the test object, the rest is scattered off of it's surface

8. the LLNL external field probes are shielded 
against recording the scattered energy

9. the coupled energy inside the test object is picked up by the internal field probes

10. the induced currents in wires inside the test object are recorded

*11. the system signal lines are measured to monitor "bird health",

12. any system or subsystem effects are recorded by the cockpit instruments and indicators by China Lake. Video and audio are also monitored.

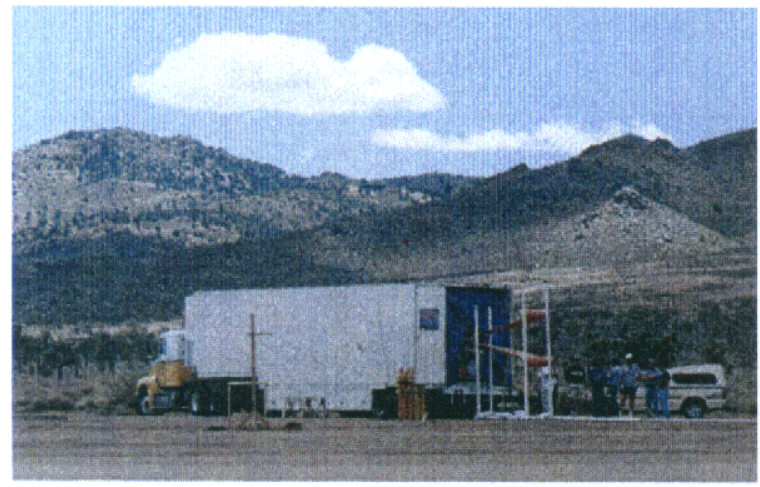

Figure 3. the AFRL wide-band pulser is contained inside of the white trailer. The output antenna is seen protruding from the end of the trailer (copper fins on white poles)

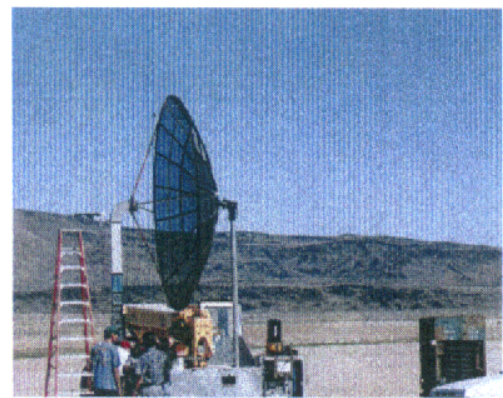

Figure 4. the ARL narrow-band pulser is connected to a twelve foot dish via rectangular waveguide. The scope sight mounted near the feed is for pointing alignment.

The fields measured inside of the helicopter were returned back to the LLNL instrumentation trailer using fiber-optic cables so that the environment of the helicopter was not perturbed. The electrical effective area of the probes themselves was quite small $\left(10^{-3} \mathrm{~m}^{2}\right)$ but in these cases, smaller is always better. The RF-to-optical conversion was performed in the battery powered electronics box placed in the lower belly of the helicopter so as not to interfere with the operation of the helicopter or the electronics in the helicopter.

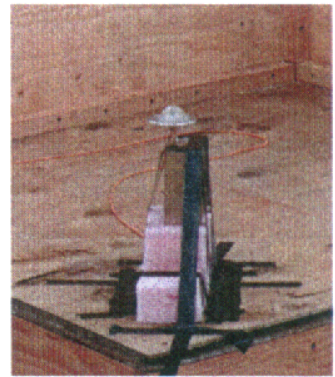

Figure 5. LLNL master trigger receives the RF energy first (all of the black tape is to prevent it from blowing away)

The life of the battery system is about twelve hours for the RF-to-optical system and about 6 hours for the analog signal line monitoring system. A change to an optically powered system would be ideal but was not available on-hand in time for this testing for the number of channels required. As it turned out, these times exceeded the testing that was actually performed on the helicopter using the pulsers over the course of the test sequence.

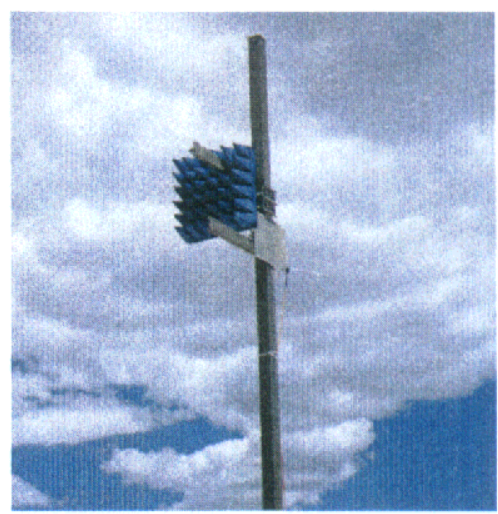

Figure 6. external field probes measure vertical and horizontal field values. The blue foam prevents interference

The fields that couple inside the helicopter were recorded by the field probes while the currents induced into the wiring of the helicopter were recorded by the high frequency current probes. These signals were then fed back to the LLNL instrumentation trailer through the fiber-optic cables. 

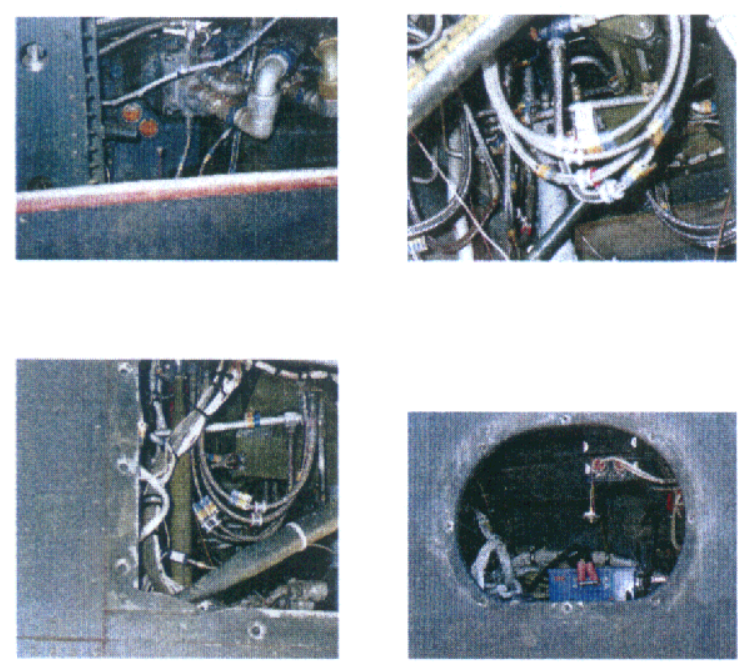

Figure 7. some of the monopoles, field probes, and current probes used to measure the RF inside the helicopter

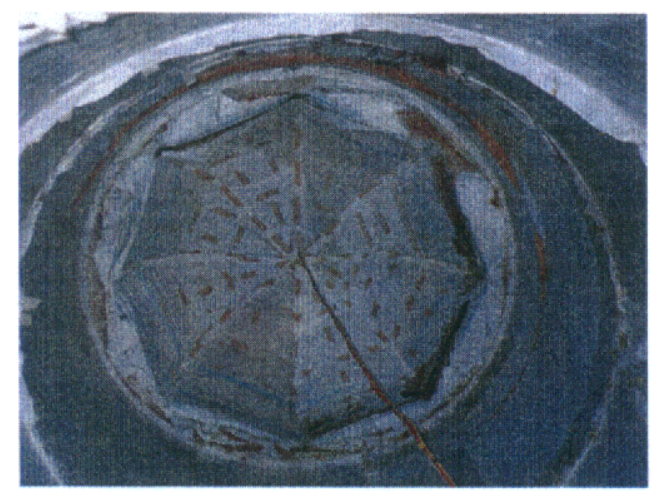

Figure 8 . inside of foam tower looking at optical fibers

The signals from all of the various probes traveled back to the LLNL instrumentation trailer via the $1.3 \mathrm{~km}$ fiber run. There, they were recorded using the high bandwidth transient scopes and stored on disk. The lower bandwidth analog signals were connected to lower bandwidth scopes and digitizers and were also stored on disk by the computer control system. Removable magneto-optical disks were used for storage and could be conveniently locked in a repository if classified data were acquired.

\section{MEASUREMENT INSTRUMENTATION}

The several of the major cavities and compartments of the helicopter were instrumented using a variety of RF probes, including non-obtrusive monopoles and field probes, to measure volumetric resonances in the internal cavities. Strategic feed lines were instrumented using high frequency current probes.

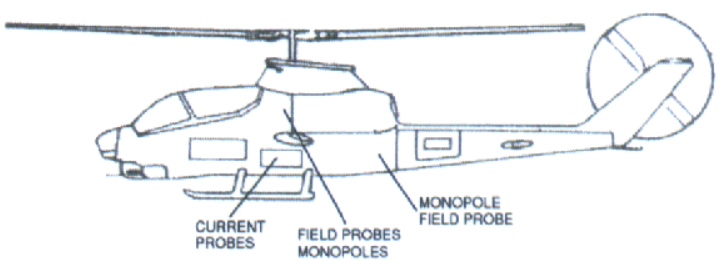

Figure 9. test point locations used in the helicopter. Test points were not instrumented in the cockpit to avoid conflicts with the China Lake instrumentation in the cockpit.

Signals from the various instrumentation packages were conveyed from the aircraft to the recording computers through a series of fiber optic transceivers to avoid the severe losses and intrusiveness into the test volume that would have occurred by using coaxial cables.
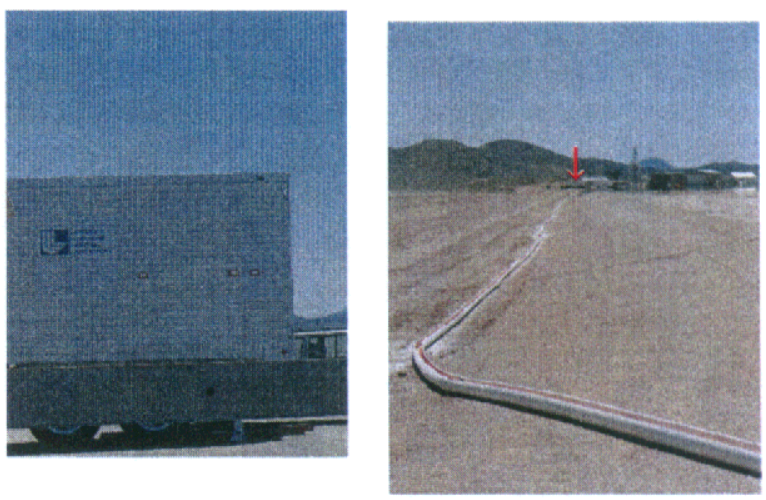

Figure 10. the LLNL instrumentation trailer was located behind the main antenna farm, $1 \mathrm{~km}$ from the test zone. The red arrow on the right is pointing to the LLNL trailer.

\section{Received RF Energy}

The RF data was recorded by the LLNL portable diagnostics trailer. The received energy was recorded after conversion from optical back to RF using the $10 \mathrm{GHz}$ converter and recorded on the transient digitizers. 


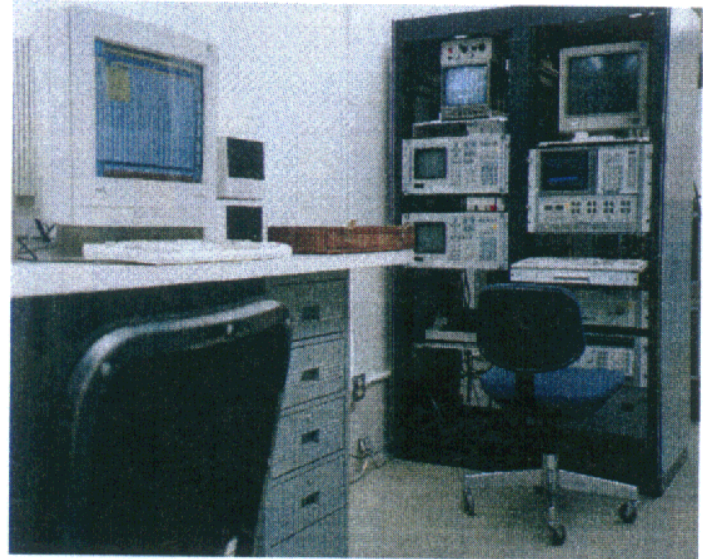

Figure 11. two of the five transient digitizers are shown in this photo. The low speed analog scopes are not visible

The bandwidth of the optical system was $10 \mathrm{GHz}$ but the transient scopes limited the final recorded data to $6 \mathrm{GHz}$. The highest frequency of operation from the HPM sources in the field was about $1 \mathrm{GHz}$ for the wide-band case (see the source section for more details) and $1.3 \mathrm{GHz}$ for the narrow-band case; each were well below the upper limit of the LLNL instrumentation system.

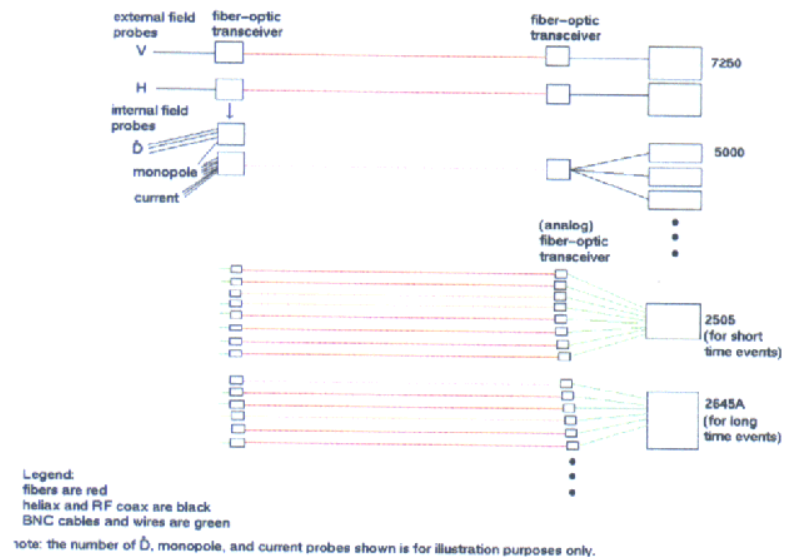

Figure 12. the system diagram showing the equipment used in the LLNL instrumentation trailer during the tests

\section{Calibration system}

The field probes used in the measurement were calibrated in LLNL's EMPEROR facility thus generating calibrations for absolute field values.

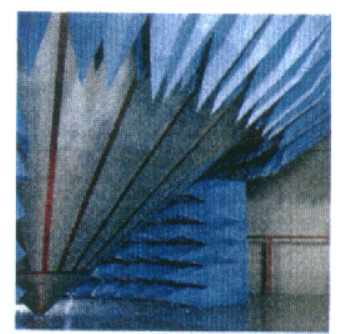

Figure 13. EMPEROR monocone facility(twelve feet tall)

The fiber-optic and RF system itself was also calibrated using swept-CW tests for calibration purposes and impulse diagnostics for verification.

\section{Incidence angles}

The initial test plan stated a goal of using three incidence angles for both vertical and horizontal polarizations:

1. a look down angle from above with the helicopter on the tower to aid in windscreen coupling mechanisms for the dominant coupling angle.

2. a look up angle from below with the helicopter on tower to utilize weapons pod and structural member coupling and included that from feed lines and interconnects. This mechanism was expected to be of secondary nature due to the existing shielding of the air frame external structural members but, unlike the windscreen effects, is prone to buildup of standing waves corresponding to the physical lengths of the connecting lines.

3. an nose-on (on-axis) illumination with the helicopter on the tower to examine main body and front compartment coupling mechanisms.

\section{Test Aircraft}

This test used the AH-1S helicopter in an instrumented configuration. The aircraft was in an operational condition and was intact and contained cabling and wiring assemblies in their original positions. The original test specimen (\#015) used in the FY96 testing was not available for use in this FY97 testing so number \#139 was used instead. The measurement criteria for selecting the test points inside the helicopter was similar as that used during the FY96 testing. The notable exception was that the cockpit area was not monitored for this test due to the amount of video and audio diagnostic equip- 
ment already in place in the cockpit. Also, the RF coupled energy into the primary power distribution system was not monitored since the helicopter was operational all of the time. Future experiments should monitor the power distribution system.

\section{DATA ACQUISITION}

For the purposes of the electromagnetic testing, a real crew was not necessary nor used. The China Lake team remotely controlled the operations of the helicopter. Data was acquired both externally from the helicopter and internally. The external measurements were made in both polarizations while the internal measurements consisted of a set of probes in the body of the helicopter. China Lake's equipment monitoring diagnostics were in the cockpit and LLNL's probes were in the main body and tail section.

Although initial plans were made for a simulated crew, eventually the China Lake team utilized a stand-alone camera and audio monitoring system and was sufficient for these tests.

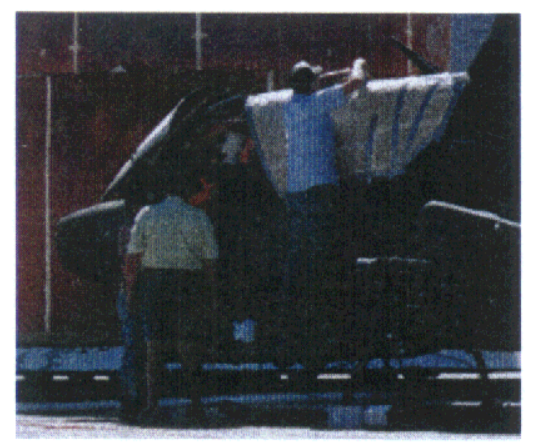

Figure 14. head of simulated crew member in the cockpit (unused). The eyes were cameras linked to the CL trailer.

\section{Field Mapping}

A limited field mapping that covered the target area was performed to determine the uniformity of the illumination in the presence of the boom, tower, surface effects, etc. This involved a 1D scan of a line of sample points across the region covered by the physical extent of the helicopter (14 meter swath) which covers the tip-to-tip span when the helicopter is in the +90 and -90 degree orientations. The field mapping was performed at the nose-on height for the respective pulsers. For the wide-band Air Force Research Lab pulser, this was about 12 feet above the ground. For the narrow-band Army
Research Lab pulser, this was about 35 feet above the ground.

For the AFRL tests, the distance from the pulser to the $+/-7$ meter measurement points varied from $87.8 \mathrm{~m}$ to 88.1 meters and so did not significantly alter the received amplitudes because of the large beamwidth of the AFRL antenna. The field across this 14 meter span varied from $5.5 \mathrm{kV} / \mathrm{m}$ to $6.6 \mathrm{kV} /$ $\mathrm{m}$.

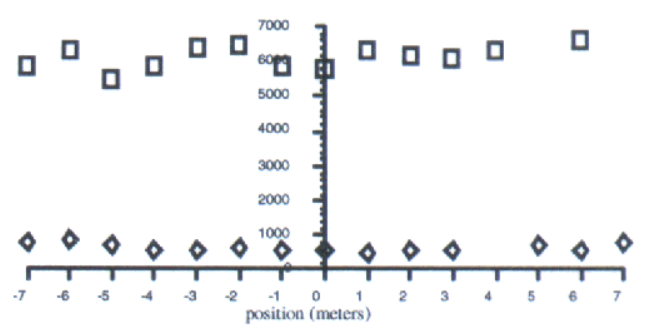

Figure 15. the AFRL co-polarized (square) and cross-polarized (diamond) peak fields across the test region are shown. The cross-polarization ratio is $18 \mathrm{~dB}$.

The AFRL tests were only performed using vertical polarization but were made at several different distance from the test object. Figure 15 was acquired at the 100 meter point $(87.8 \mathrm{~m}$ from the pulser to the LLNL field measurement post). LLNL only acquired swath data at this distance since the closer two distances were too close.

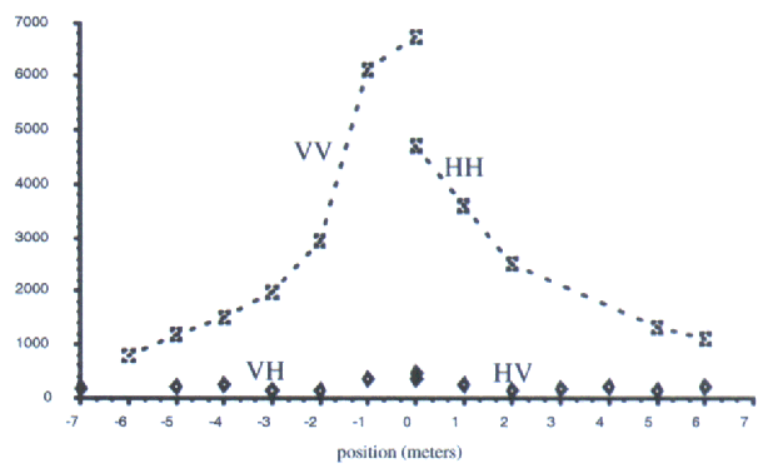

Figure 16. The ARL peak fields across the test region. Note that the right hand swath was acquired with the pulser in the $1^{\text {st }}$ configuration (horizontal polarization), while the left hand swath was acquired in the $2^{\text {nd }}$ configuration (vertical polarization). The ARL pulser was at the $58 \mathrm{~m}$ point (45.8 $\mathrm{m}$ from the pulser to the LLNL field measurement post)

The plot showing the field mapping for the ARL pulser is shown in Figure 16. Notice that the positive swath was acquired with the pulser in one configuration (transmitting $\mathrm{H}$ polarization) while the 
other swath was acquired while the pulser was transmitting in the other polarization ( $\mathrm{V}$ polarization). The asymmetry in the beam can be due to the asymmetry in the ARL feed-horn waveguide, incomplete dish illumination, ground bounce effects, etc. The cross polarization ratio is $22-25 \mathrm{~dB}$ in the main beam of the antenna.

\section{TRANSMITTED WAVEFORMS}

The transmitted waveforms for the AFRL pulser are shown below. These waveforms were typical of the family of waveforms generated during the entire test sequence. The shape of the waveforms is consistent from pulse to pulse.

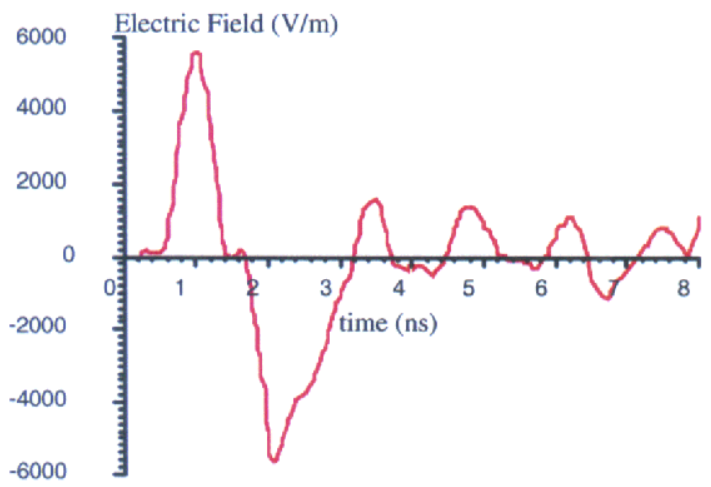

Figure 17. AFRL time domain vertically polarized waveform as recorded by LLNL's measurement system at nose-on height, 87.8 meter distance.

The cross polarization factor between vertical and horizontal polarizations was $-18 \mathrm{~dB}$. The cross polarized waveform is shown in the figure below:

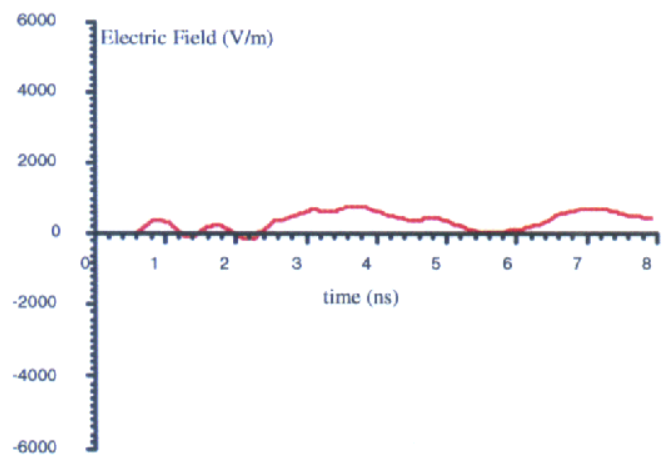

Figure 18. AFRL time domain cross polarized waveform as recorded by LLNL's measurement system at nose-on height, 87.8 meter distance.

Note especially the time delay of the "peak" in the cross-polarization waveform. A longer time sampling showed this to be (the truck and/or the resistors. Show waveform illustrating this and state the time and resonance frequency.)

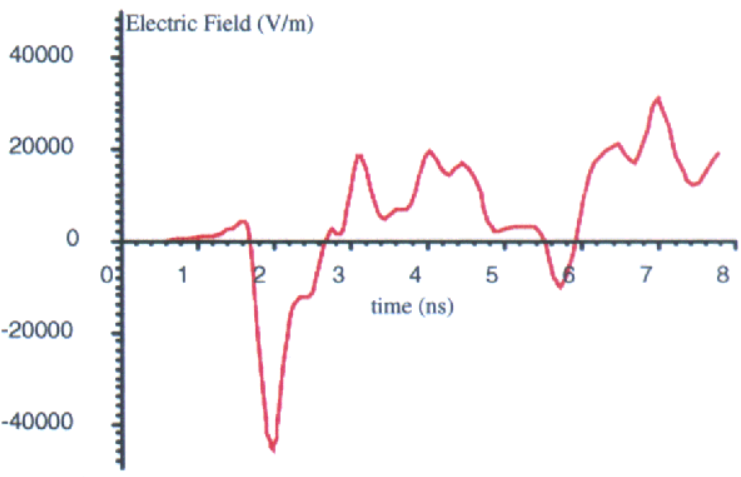

Figure 19. (uncorrected) time domain radiated AFRL waveform as recorded by AFRL's measurement system at 2.57 meter height, 10 meter distance.

Using the $1 / \mathrm{r}$ scale factor for far field measurements, the ratio between the LLNL measurement of $5.6 \mathrm{kV} / \mathrm{m}$ at 87.8 meters and the AFRL measurement of $45 \mathrm{kV} /$ $\mathrm{m}$ at 10 meters is:

$$
5.6 \mathrm{kV} / \mathrm{m} \cdot 87.8 \mathrm{~m}=492 \mathrm{kV} \approx 45 \mathrm{kV} / \mathrm{m} \cdot 10 \mathrm{~m}
$$

So the agreement of the two teams measurements after the AFRL waveform correction, compounded by the linearity error at the close-in distance and any ground bounce that AFRL experienced, is quite good at $9 \%$. The differences in the time domain waveform shapes (Figures 17 and 19) are due to an integration problem in the AFRL system. We corrected the AFRL waveform to obtain Figure 20.

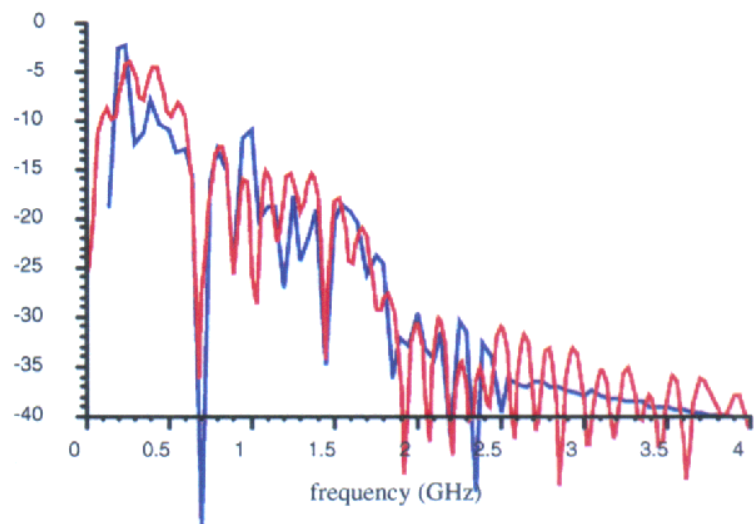

Figure 20. spectra of Figure 17 and the (corrected) AFRL waveform [in blue] agree well and have peaks between 200 and $500 \mathrm{MHz}$. The values at $1-2 \mathrm{GHz}$ are $10-20 \mathrm{~dB}$ down while the values at $2-4 \mathrm{GHz}$ are $25-30 \mathrm{~dB}$ down. 
The transmitted waveforms for the ARL narrowband pulser are shown below. Although this was a pulsed-CW pulser, the data were recorded in the time domain to be consistent with the measurements that LLNL performed on the AFRL pulser the previous week.

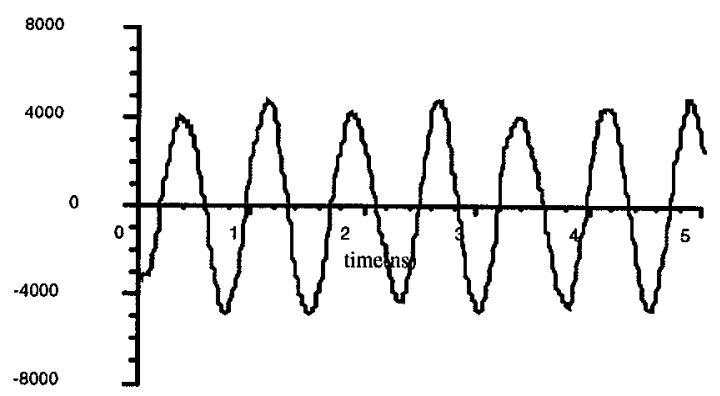

Figure 21. time domain $1.32 \mathrm{GHz}$ ARL waveform as recorded by LLNL's measurement system. This is a 5 ns sample from the $2 \mu$ s burst.

The spectrum of the ARL narrow-band waveform is shown below and was qualitatively confirmed by ARL's monitoring of their source's spectrum during the testing.

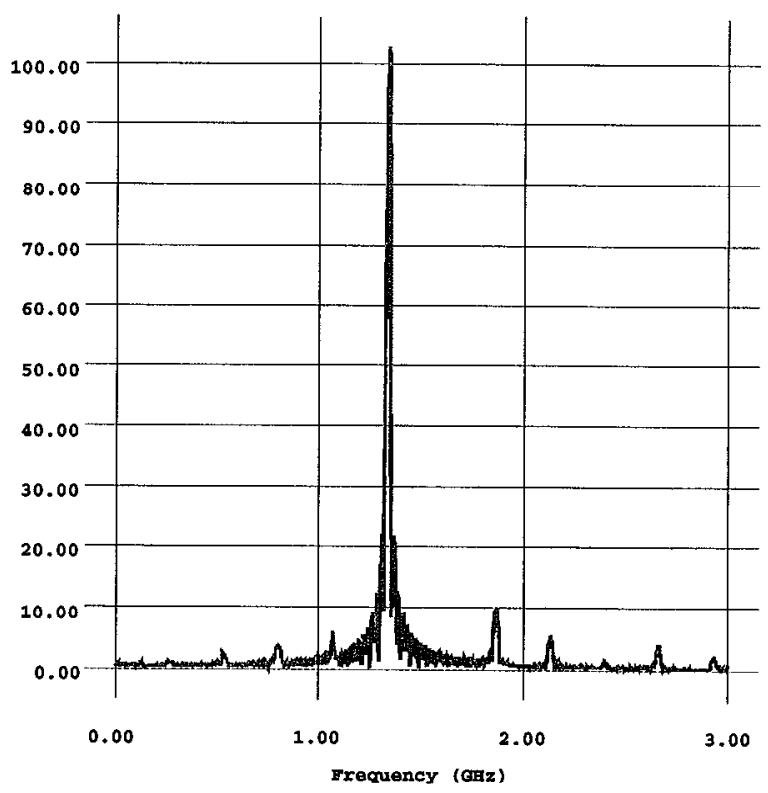

Figure 22. spectrum of the ARL waveform (Figure 21) for $1.32 \mathrm{GHz}$. The peak in this graph is at $1.334 \mathrm{GHz}$.

\section{COUPLED WAVEFORMS}

The probes that were inside the helicopter acquired waveforms during the ARL narrow-band testing only since no coupling measurements were made on the helicopter using the wide-band AFRL source. Additionally, only nose-on illumination at 0 degrees was used during the narrow-band testing. Since the probes were in the aft section of the helicopter, and the antenna beamwidth was only a few meters, and the front sections shielded the aft sections, then there was not sufficient $\mathrm{S} / \mathrm{N}$ to determine the field strengths.

\section{SAFETY}

Since LLNL personnel access to the helicopter needed to occur during the field mapping, adequate precautions were maintained to insure that both physical and clectromagnetic safety guidelines were followed.

For physical safety, the requirements of Naval Air Warfare Center, China Lake, Naval Weapons Center (Instruction 5100.6C, Safety and Industrial Hygiene Manual), and the Lawrence Livermore National Laboratory, (LLNL Health and Safety Manual, UCRLMI-118839) were observed. Special notes and operating guidelines were outlined in detail in the operations document for the tower and include physical access guidelines for the tower, rotation of the aircraft on the tower, operations of personnel while on the tower with the aircraft, and physical hazards imposed by cabling running to/from the tower platform. Since this tower is specifically designed not to interfere with the electromagnetic wavefront, then the amount of physical barriers that were possible was limited, thus access to the tower platform will be limited to essential personnel. In practice, the access to the top of the tower was limited only to China Lake operations personnel and LLNL electronics technicians using the bucket truck and harnesses.

For electromagnetic safety reasons, precautions were taken to ensure that unintentional exposure and incidental exposure would be in accordance with the limits in LLNL's Health and Safety Guidelines ${ }^{3,4}$. It was not the intent of the testing to intensionally radiate personnel. The following summary is reproduced here for reference purposes only: 


\begin{tabular}{|l|c|c|c|}
\hline & $\begin{array}{c}\text { Power } \\
\text { Density } \\
\left(\mathrm{W} / \mathrm{m}^{2}\right)\end{array}$ & $\begin{array}{c}\text { Electric } \\
\text { Field } \\
(\mathrm{V} / \mathrm{m})\end{array}$ & $\begin{array}{c}\text { Averaging } \\
\text { Time } \\
(\mathrm{min})\end{array}$ \\
\hline $\begin{array}{l}30-100 \\
\mathrm{MHz}\end{array}$ & 10 & 61.4 & 6 \\
\hline $\begin{array}{l}100-300 \\
\mathrm{MHz}\end{array}$ & 10 & 61.4 & 6 \\
\hline $\begin{array}{l}300-3000 \\
\mathrm{MHz}\end{array}$ & $\mathrm{f}_{\mathrm{MHz}} / 30$ & - & 6 \\
\hline $\begin{array}{l}3000- \\
15000 \\
\mathrm{MHz}\end{array}$ & 100 & - & 6 \\
\hline
\end{tabular}

During the entire test sequence, the majority of LLNL personnel remained in the LLNL instrumentation trailer ( $1 \mathrm{~km}$ away from the test site). The exception was during the field mapping. In this case, LLNL personnel remained inside the China Lake shielded trailer during HPM transmission.

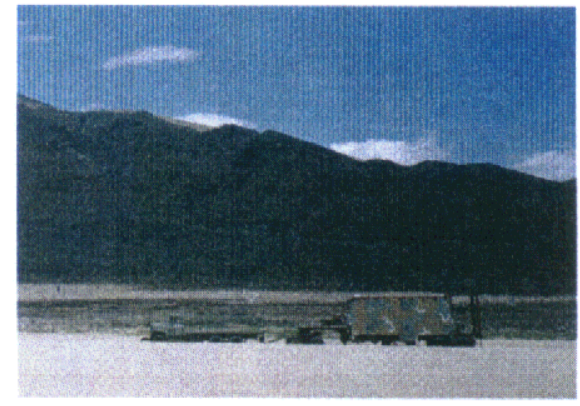

Figure 23. China Lake shielded trailer. The analog and video cockpit signals were monitored by the China Lake team from their shielded trailer. When LLNL personnel were near the test region, they were inside the trailer.

\section{CONCLUSIONS}

1. the instrumentation and field diagnostics of the LLNL system was demonstrated to meet the needs of a typical live fire test activity for static objects.

2. direct comparisons between the AFRL wide-band system and the ARL narrow-band is difficult because of the different frequency bands of operation. Due to this frequency difference, the AFRL team did have to get closer (thus higher power on-target) than the ARL team did to cause significant effects.
3. several problems with the HPM pulsers prevented a full set of measurement data to be acquired from the helicopter.

4. the wide-band test was vertically polarized while the narrow-band test was horizontally and vertically polarized. Without horizontal wide-band data it is difficult to make direct comparisons based on polarization effects.

\section{RECOMMENDATIONS}

1. HPM sources should be characterized and tested before asset testing begins. Unlike leading-edge HPM weapon development activities, sources as part of a facility should be repeatable and easily maintained. Any leading-edge HPM weapons can be brought in as needed.

2. a standoff distance of several hundred meters is required for live fire testing. The motivation of LFT\&E testing is to test the asset, not an HPM weapon.

3. both vertical and horizontal polarizations should be transmitted and measured.

4. three illumination angles (from below, on-axis, from above) should be used since they represent typical illumination scenarios for airborne platforms.

5. the monitoring of equipment signal lines for " asset health" is vital and should be done during testing. This is necessary for upset detection.

6. optically powered, remotely controlled diagnostics should be used to increase testing flexibility for static targets. Self contained battery powered diagnostics should be used for dynamic targets.

\section{ACKNOWLEDGMENTS}

The authors would like to thank Mark Henderson, John Lelis, and the JR support crew for their efforts in connection with the testing issues, the AFRL and ARL teams for their pulser efforts, and the LLNL EM Lab staff for their calibrations and diligence while both at LLNL and while in the field.

Work performed under the auspices of the U.S. Department of Energy by Lawrence Livermore National Laboratory under Contract W-7405-ENG-48. 


\section{REFERENCES}

${ }^{1}$ Balanced Technology Initiative Comparison of Ultra Wideband (UWB) and High Power Microwave (HPM) Susceptibility of Rochelle Salt, Lawrence Livermore National Laboratory, Jan. 1992, UCRL-ID-111676.

${ }^{2}$ A. Poggio, R. Zacharias, S. Pennock, C. Avalle, R. Sharpe, K. Kunz, C. Meissner, "NASA FBL / PBW Program NASA Boeing 757 Low Power On-the-Ground-Tests,"' Lawrence Livermore National Laboratory, UCRL-ID-118775, Oct. 1994.

${ }^{3}$ B. Smith, "Low frequency testing of the Electromagnetic [physical] model of the Comanche Airframe [frequencies $>100$ kHz]", Army Research Lab, 1996.

${ }^{4}$ W. G. Magnuson, R. J. King, W. C. Ng, “An Overview of Circuit Analysis and Experimental Validation of HPM Upset and Burnout," $4^{\text {th }}$ National Conference on High Power Microwave Technology for Defense Applications, Naval Post Graduate School, Montery, CA, May 9-12, 1988. Lawrence Livermore National Laboratory UCRL-97845.

${ }^{5}$ W. Ng, R. Zacharias, "Composite material shielding effectiveness for RAH-66," Lawrence Livermore National Laboratory, part of the briefing package presented to James O'Bryon, Live Fire Test Office, Office of the Secretary of Defense, Jan. 17, 1996, and Comanche TIWIG, Jan 24, 1996

${ }^{6}$ W. Ng, "HPM Testing of Electronic Components," Lawrence Livermore National Laboratory, UCID-21687, May 1989.

${ }^{7}$ K. Griffin, "EMP Susceptibility of Various Cables," Lawrence Livermore National Laboratory, LEN 22380, Oct. 1989.

8 " Nonionizing Radiation and Fields," from the LLNL Health and Safety Manual, section 26.12.

9، "Electrical Safety," from the LLNL Health and Safety Manual, Chapter 23.

${ }^{10}$ S. D. Nelson, "Fluence and Helicopter Status Measurements in support of the HPM Test of the AH-1S Cobra Helicopter," Lawrence Livermore National Laboratory, May 27, 1997.

${ }^{11}$ Carlos Avalle, Ray King, Eric Reid, internal communication on the performance of EMPEROR, Lawrence Livermore National Laboratory, February 9, 1990.

${ }^{12}$ R. A. Anderson, "Calibration of the Prodyne AD-70 Ddot probe," Lawrence Livermore National Laboratory, June 6, 1990. 
APPENDIX -- misc, calibration data

Fiber optic system

The following information is provided for documentational purposes. Since timing of the transient wide-band pulses is important, the lengths (hence the travel times) of the fiber optic cables were measured.

\begin{tabular}{|c|c||c|c|}
\hline cable & length $(\mathrm{m})$ & cable & length $(\mathrm{m})$ \\
\hline 1 & 1320 & 12 & 1314 \\
\hline 2 & 1325 & 13 & 1303 \\
\hline 3 & 1305 & 14 & 1305 \\
\hline 4 & 1311 & 15 & 1307 \\
\hline 5 & 1325 & 16 & 1302 \\
\hline 6 & 1306 & 17 & 1306 \\
\hline 7 & 1315 & 18 & 1314 \\
\hline 8 & 1314 & 19 & 1304 \\
\hline 9 & 1309 & 20 & 1303 \\
\hline 10 & 1308 & trigger & 1269 \\
\hline 11 & 1305 & spare & 1317 \\
\hline
\end{tabular}

The above table shows the lengths of cables for the analog I/O system that was used. The cables were specified to be $1.3 \mathrm{~km}$ (the lengths were surprisingly accurate) and the shortest cable from the group was chosen to be the trigger cable. The trigger cable provides the mastcr trigger from the transmitted waveform. The trigger signal had to arrive at the LLNL trailer $90 \mathrm{~ns}$ before the data signals. With a cable propagation of $4.98 \mathrm{~ns} / \mathrm{m}$, the trigger signal arrived 95 ns (plus the positional placement air propagation factor and the difference in delays in the equipment boxes) before the first data signal.

\begin{tabular}{|c|c|c|c|c|}
\hline telemetry box & $\# 1$ & $\# 2$ & $\# 3$ & spare \\
\hline \hline control 1 & 1301 & 1313 & 1300 & \\
\hline control 2 & 1301 & 1300 & 1300 & \\
\hline data & 1288 & 1288 & 1288 & 1286 \\
\hline
\end{tabular}

The data and control lines for the white RF telemetry boxes were composed of both single-mode and multi-mode fibers. The control lines constitute the digital communication between the instrumentation trailer and the boxes. These lines control the multichannel capability of the boxes.

The fiber optic lines from the telemetry boxes connected to the LLNL instrumentation trailer via the 1.3 $\mathrm{km}$ fiber optic cables. The system response of the telemetry box plus the fiber optic system is shown below:

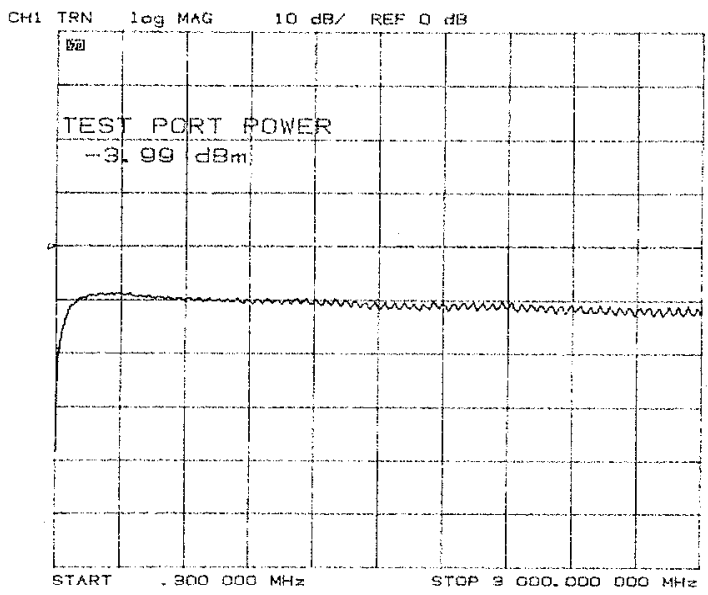

Figure 24. system response of fiber-optic telemetry system with $1.3 \mathrm{~km}$ of fiber-optic cable and the Veritech amplifier $(\# 87,88$ ) shows a flat frequency response (to within $2 \mathrm{~dB}$ ) above $400 \mathrm{MHz}$.

and represents the system response from the RF input port of the telemetry box to the RF output port of the fiber-optic system. This output was then fed into the transient digitizers or the network analyzer as appropriate.

\section{Linearity curves}

The high frequency linearity of the RF telemetry system is shown in Figure 25 and is a plot of the output voltage (ordinate) vs. the input voltage (abscissa). During the helicopter testing, RF pads were added to the input lines to keep the input voltage in the highly linear region from -0.3 to +0.3 volts yielding an output in the -1.5 to +1.5 volts range. These pads were then backed out of the final calculation. This figure shows the response curves for telemetry link systems \#1 (green squares) and \#3 (brown diamonds). The amplifiers built into the system provide for the high output levels. 


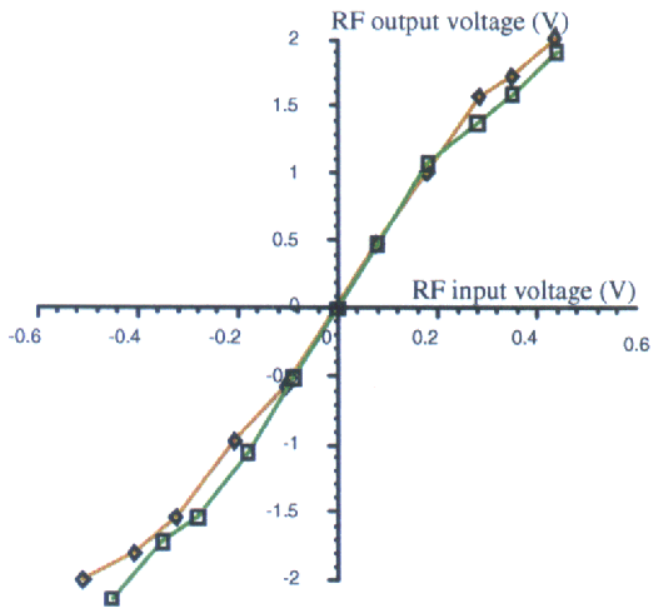

Figure 25. input/output linearity of the telemetry system

Note that the input voltage (Vin) is the RF input into a channel in the telemetry box while the output voltage (Vout) is the RF voltage out of the system (and into the transient digitizer) in the LLNL instrumentation trailer at the other end of the $1.3 \mathrm{~km}$ long fiber optic cable.

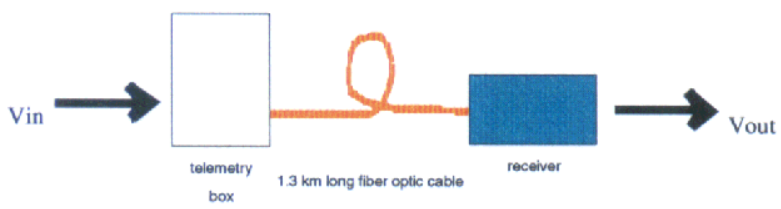

Figure 26. system diagram showing the input to the white telemetry box and the output from the blue receiver box

The signal from the probe (optionally) goes through an input pad and then this signal, Vin, goes into the white multi-channel RF telemetry box. It is then transmitted along the fiber-optic cable, is fed out of the receiver subsystem, Vout, and goes into the transient digitizers in the LLNL instrumentation trailer. The white boxes were on the LLNL field measurement post (see Figure 6) measuring the transmitted waveform from the pulsers and were also inside the helicopter connected to the internal probes (see Figure 7).
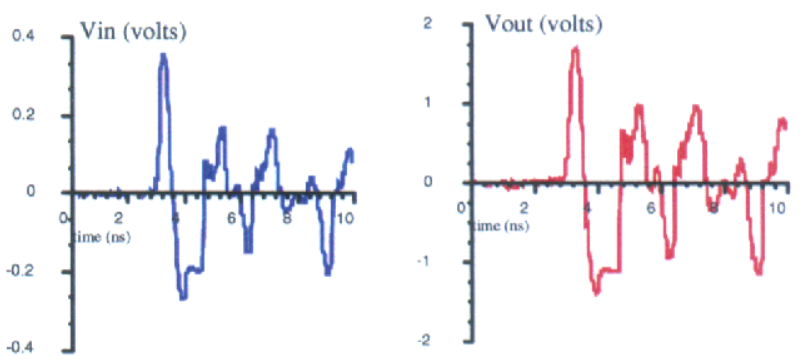

Figure 27. raw Vin and Vout (input and output) time domain waveforms

The above figures show the input and output voltages as recorded by the telemetry system. The difference between the calibrated waveform is shown in the next figure. Vin is used to determine the electric field at the field probe.

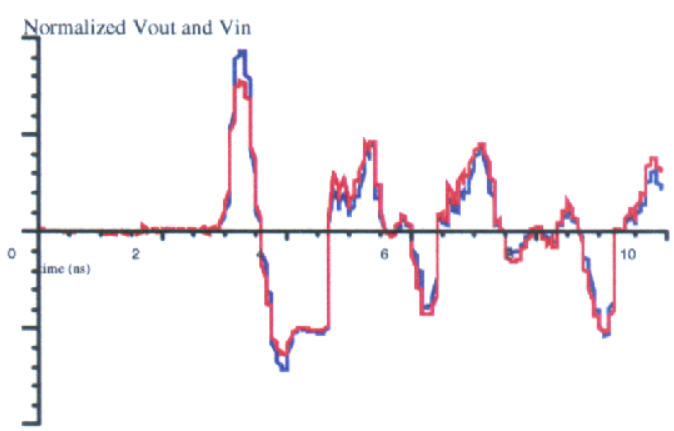

Figure 28. input/output waveforms after linearity correction

For comparison, the normalized input and output voltages are shown. There is a small amount $(15 \%)$ of change in some of the peak amplitudes but otherwise the waveform shapes are the same. Note that this is still the unintegrated waveshapes from the Ddot.

Then, by removing the characteristics of the pad that was on the input to the white telemetry box (to keep the white box in the linear region) and applying the probe calibration functions from EMPEROR (see Figure 13) we get the time domain electric field waveform.

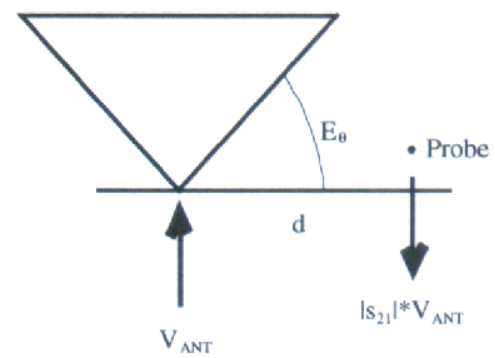

Figure 29. probe calibration system diagram 
The electric field at a measurement point a distance $d$ along the ground plane from the apex experiences an electric field intensity given by ${ }^{11}$ :

$$
E_{\theta}=\frac{V_{\text {ANT }}}{0.8269 \cdot d}
$$

For reference, the number 0.8269 is a characteristic of the facility and comes from

$$
\ln \tan \frac{\theta_{\mathrm{hc}}}{2}
$$

where $\theta_{\mathrm{hc}}$ is 47.25 degrees that corresponds to the $49.6 \Omega$ input $\left(60 \ln \cot \theta_{\text {hc }} / 2\right)$ and has been verified experimentally over the years.

This allowed the calibration of the probes used during the HPM testing to be mapped to absolute electric field strength. In the low frequency portion of the spectrum $(<3 \mathrm{GHz})$ these Ddot probes operate in their differentiating regime and have a response of the form $^{12}$.

$$
\left|\mathrm{s}_{21}\right| \approx \mathrm{\kappa} \cdot \mathrm{f}
$$

where $\kappa$ is the slope in frequency space. Combining these terms yields

$$
E_{\theta}=\frac{e_{0}}{\left|s_{21}\right| \cdot 0.8269 \cdot d} \approx \frac{e_{0}}{\kappa \cdot f \cdot 0.8269 \cdot d}
$$

Thus for a probe in free space, and observing that in the frequency domain

$$
\dot{\mathrm{E}}=\frac{d}{d t}\left(\mathrm{E}_{0} \mathrm{e}^{\mathrm{j} \omega \mathrm{t}}\right)=j \omega \mathrm{E}_{0} \mathrm{e}^{\mathrm{j} \omega \mathrm{t}}=j \omega \mathrm{E}=\mathrm{j} 2 \pi \mathrm{fE}
$$

and applying substitution

$$
\dot{E}=\frac{2 \pi e_{0}}{\kappa \cdot 0.8269 \cdot d}
$$

we get the following calibrated equation:

$$
E=\frac{2 \pi}{\kappa \cdot 0.8269 \cdot d} \int e_{0} d t
$$

which relates the time varying real voltage from the probe, $\mathrm{e}_{0}$, to the electric field that it experiences, $\mathrm{E}$. The following calibration parameters were measured for the external field probes used during the testing:

\begin{tabular}{|c|c|c|}
\hline & $\kappa$ & $d$ (meters) \\
\hline Ddot \#34 & $1.262 \mathrm{e}-12$ & 2 \\
\hline Ddot \#43 & $1.065 \mathrm{e}-12$ & 2 \\
\hline Ddot \#57 & $1.198 \mathrm{e}-12$ & 2 \\
\hline
\end{tabular}

By applying the above equation, and integrating with respect to time, we get the time domain electric field waveforms (see Figures 17, 18, 21).

\section{Harmonic distortion for $\mathrm{CW}$ data}

For the $\mathrm{CW}$ measurement sequence, the harmonic distortion in the white telemetry box was measured. Figure 30 shows the fundamental frequency $(\sim 1.3$ $\mathrm{GHz})$ and a harmonic at twice the fundamental ( $\sim 2.6$ $\mathrm{GHz}$ ) which is about $20 \mathrm{~dB}$ below the primary signal.

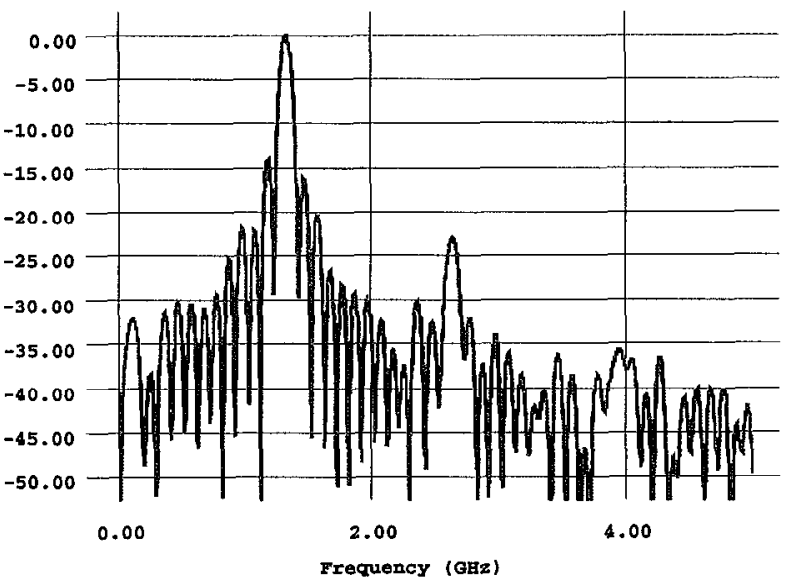

Figure 30. harmonic distortion of the telemetry system for CW operation is low. The fundamental is at $1.3 \mathrm{GHz}$ and the harmonic at $2.6 \mathrm{GHz}$ is about $20 \mathrm{~dB}$ lower.

Internal probe calibration

The calibration data for the single ended Ddot probes \#33 (left) and \#36 (right) are shown in the following figures. The calibration coefficients for these probes are shown in the subsequent table; note especially the change in the distance parameter: 

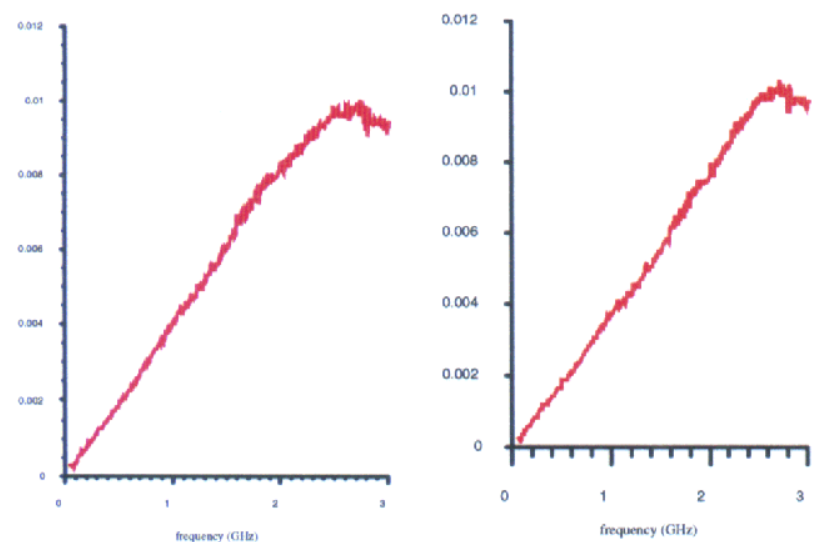

Figure 31. probe calibration curves for the internal Ddots

\begin{tabular}{|c|c|c|}
\hline & $\kappa$ & $\mathrm{d}$ (meters) \\
\hline Ddot \#33 & $4.10 \mathrm{e}-12$ & 1 \\
\hline Ddot \#36 & $3.875 \mathrm{e}-12$ & 1 \\
\hline
\end{tabular}

The subresonant monopoles used during the FY97 testing are the same as those used during the FY96 low power field activities. For the frequency band used for the FY97 tests ( $\mathrm{f}<1.5 \mathrm{GHz}$ ), the monopoles have a linear characteristic performance:

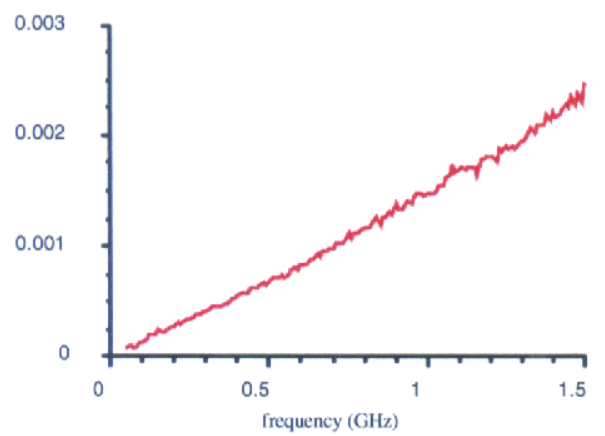

Figure 31. monopole calibration curve for mono\#1. Factors for the other monopoles are shown in the next table.

but is non-linear for frequencies above $1.5 \mathrm{GHz}$. All frequencies used during this test were below $\sim 1.3$ $\mathrm{GHz}$.

\begin{tabular}{|c|c|c|}
\hline & $\kappa$ & $\mathrm{d}$ (meters) \\
\hline monopole \#1 & $1.52 \mathrm{e}-12$ & 1 \\
\hline monopole \#2 & $1.50 \mathrm{e}-12$ & 1 \\
\hline monopole \#3 & $1.60 \mathrm{e}-12$ & 1 \\
\hline
\end{tabular}

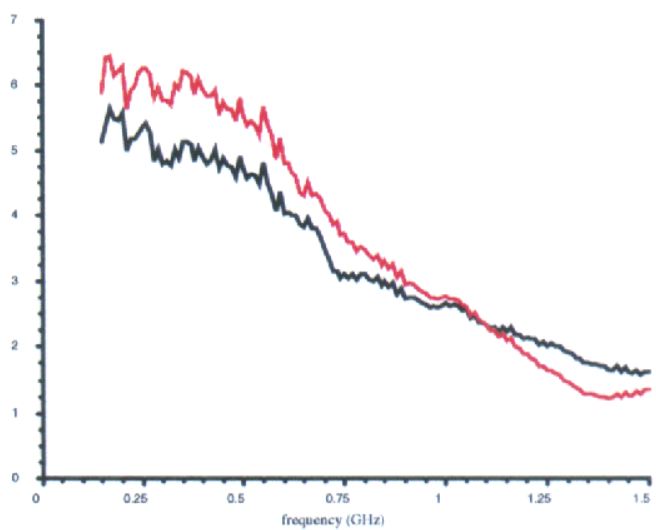

Figure 32. performance of the high frequency current probes shows the expected roll-off at higher frequencies.

The responses of CT1\#1 [red] and CT1\#2 [black] are shown above. At the $1.3 \mathrm{GHz}$ point (where they were used during the narrow-band ARL testing) the responses were $1.9 \mathrm{mV} / \mathrm{mA}$ and $1.5 \mathrm{mV} / \mathrm{mA}$ respectively. The probes were not used during the wideband sequence since the testing did not get to that point. 